\title{
The Effect of Open Book Test Model in Improving Students' Learning Motivation
}

\author{
Akbar Iskandar \\ STIMIK AKBA \\ Makassar, Indonesia \\ akbar.iskandar06@gmail.com
}

\begin{abstract}
The purpose of this research were to describe the students' learning motivation on the statistics course. This research also determine the differences in students' learning motivation between the classes of a given opened test model and a closed book test model at STMIK AKBA. The type of the research was an experimental research. Data were collected through observation and questionnaire method. The total sample was 50 students with cluster sampling technique. Data analysis used descriptive and inferential statistics. The research found that students' motivation to learn with a given model of opened book test was higher than their motivation with a closed book test model. It was supported by the result of statistical inferential tests where there was a difference between the students' learning motivation given opened book test model with the close book test model in the statistics course in STMIK AKBA.
\end{abstract}

\section{Keywords-model; test; open book; motivation}

\section{INTRODUCTION}

Msila and Rakes state that the test by opening a book can provide learning opportunities for the students to have a more realistic emphasis on high-level thinking skills [1], [2]. The students will be asked to provide a solution to a problem that occurs. Thus, it requires the more mature preparation compared to those of close books model. Furthermore, motivation to learn plays a critical role in learning activities both in school and in college. The motivation is a complex part of human psychology and behavior that affect how individuals choose to invest time, energy and mind to achieve something. The higher the person's goals to be achieved the greater the motivation. If this is associated with students' learning motivation, the greater the motivation of the students, the more powerful it learning activities.

Based on the results of preliminary observation found that most students consider that the statistics courses at STMIK AKBA filled with computation that is not much different from the subjects of mathematics. It also requires high knowledge of analytical techniques. Furthermore, the grade of learning outcomes of the statistics course on the first semester of 2014/2015 year at STMIK AKBA shows the value of A was $5 \%$, B by $20 \%, \mathrm{C}$ by $50 \%$, D by $10 \%$ and $\mathrm{E}$ was $15 \%$.

This research tried to change the views of students on the statistics course by providing opened book test model during the final exam. This means that all the participants are allowed to take and open the reference books in the exam. With this test model, students will be motivated to learn independently and prepare statistical material from various sources. The results of this study were supported by the research of Agarwal and Roediger III and Mathew which states that students who take the test by opening the book will be more active [3], [4]. They also have better performance than those who test by closing the book. In addition to the opened book test model, the students would be more pleased than closed the book model tests.

\section{METHOD}

This type of research is a kind of true experimental study. The subjects in this study were the students majoring in informatics engineering that take the statistics course in academic year 2016/2017. The object of this study were students of Class A and Class B. The data was collected by observation and questionnaire method. The total sample was 50 students. Data analysis used descriptive statistics and inferential with the help of SPSS version 20.00. Decisionmaking criteria analysis results are:

If $\mathrm{t}$ arithmetic $\geq \mathrm{t}$ table, or if $\mathrm{p}$-value $<\alpha$, then reject $\mathrm{H} 0$ and accept the alternate hypothesis. Otherwise, we accept the null hypothesis.

\section{RESULTS AND DISCUSSION}

The implementation of this research has been made based on the predetermined schedule. If the stages of research meet the standards of research such as validity and reliability of instruments, then it can be tested to the 20 respondents. The results of point 1 do not meet the valid criteria and should be discarded because of the significant value of the results of the analysis are less than 0.05 . The second item until the 26 item of the instrument belongs to the valid category because the significance value is smaller than alpha 0.5 . The reliability of the results obtained a value of $0.970(0.970>0.70)$ where the number is greater than the prescribed standards in the category of reliable namely 0.70 Cronbach's Alpha then it categorized as reliable [5]

Furthermore, before further analysis, the data should be tested in normal and homogeneity test with SPSS 20.00. Based on the data normality test results, it appears that all data is in the normal distribution due to the significant value of 0.390 control class and experimental class of 0502 which is higher than 0.05 . The significance value (sig) in homogeneity test is 0002 , where the figure is smaller than an alpha of 0.05 . Therefore, it can be concluded that both data have a different variant (not homogeneous). 
The results of the descriptive statistical analysis showed that the respondents of experimental class learning motivation had an average score of 107.40, standard deviation 7.81, variance 60.99 , range 22.00 , minimum value 97.00 and a maximum value of 119.00 . Furthermore, the average score control class is 76.70 with standard deviation 5.21 , variance 27.11, range 22, the lowest value of 68 and a maximum value of 90.00. Furthermore, the motivation of respondents about the criteria used in this study is divided into four criteria, namely: excellent, good, less good and bad. The distribution of scores for each criterion is presented in Table 1.

TABLE I. RANGE OF SCORES AND STUDENT LEARNING MOTIVATION CRITERIA

\begin{tabular}{|l|l|}
\hline \multicolumn{1}{|c|}{ Range Score } & \multicolumn{1}{c|}{ Criteria } \\
\hline Score $>99.9$ & Very High \\
\hline $75<$ Score $\leq 99.9$ & High \\
\hline $50.1<$ Score $\leq 75$ & Low \\
\hline Score $\leq 50.1$ & Very low \\
\hline
\end{tabular}

Based on Table 1, it can be assumed that in the experimental class there were $25 \%$ of the students who have high learning motivation and $75 \%$ of the students have very high motivation to learn. Whereas in control classes there were $46.7 \%$ of the students who have very low motivation to learn and $53.3 \%$ of the students have low motivation. Parametric Statistical Tests of the Independent Samples Test used in this study to examine whether there is a difference between learning motivation in the experimental class with control class using the SPSS 20.00 version.

Based on the analysis of data found, t-count was 15.440. While t-table at alpha was 5\%: $2=2.5 \%$ (2 sides test) with degrees of freedom (df) n-2 or 50-2 was 48, so t-table obtained was 2.014 , since $\mathrm{t}$-count $>\mathrm{t}$ table $(15.440>2.014)$ and $\mathrm{p}$ value $<\alpha(0.002<0.05)$ so H1 was accepted. It means that there was a difference in students' learning motivation between experimental class and the control classroom. The research found that there was a difference between the students' learning motivation of given opened book test model with a closed book test model. This proves that for the statistics course that using an opened book test model have a significant influence on the improvement of students' learning motivation rather than closed book test model on the statistics course exam.

On the previously results of the descriptive analysis that the classes given the opened book model test have better motivation to learn than those in the control class. In the experimental class there were five students $(25 \%)$ who have high motivation to learn, and 15 people students (75\%) who have very high motivation to learn. While in the control classes with a closed book test model, the motivation to learn was categorized as high with 16 students (53\%) and low category with 14 students (46.7\%).

Furthermore some researchers Block and Gharib et al. add that the test model with opened books universally reduces the anxiety of students in examinations as well as increasing pleasure in promoting student learning outcomes [6], [7]. More some also Green, Ferrante, and Heppard explained that the opened book model test makes students better prepare themselves for the exam and further increase the frequency of learning [8]. Essential learning is a process through exercise by the experience of a teacher and the learning outcomes that we do today will be useful in the future. For that, strong and weak motivation to learn of someone depends on what is expected in the coming period and influenced by various factors such as the lecturers, methods, environment, ideal, and learning ability [9].

Feng, Fan and Yang and Sogunro argue that to improve student achievement, it needed to increase the motivation in the learning process because motivation and achievement will mutually affect one another [10], [11]. If a student is interested in a subject, then he will be strived to be the best and active in learning, but if the opposite happens, it is difficult to find the right method to increase learning motivation. The results of a particular test can be used a base to give feedback, both for the person taking the test as well as for the educators who attempted to transfer his ability to learners. However, the results of the measurement process can be used in the provision of feedback if it had been through the so-called interpretation. Myyry and Joutsenvirta, explains that the assessment plays a major role in higher education due to determine the maturity of the students in preparing for the job world that must be proven by the results of their assessment [12].

\section{CONCLUSION}

Based on the results of the research and discussion on the effect of the opened book model test to motivate students' learning, it can be concluded that the students' learning motivation in experimental class with the opened book model test is better than those who are given the closed book model test. This is supported by the results of the analysis of Independent Samples Test (t-test) which states that there is a difference between experimental and control class in their learning motivation.

\section{REFERENCES}

[1] V. Msila, 'Assessment in a Transforming Higher Learning Institution: A Case for Open-Book Examinations', Mediterr. J. Soc. Sci., vol. 5, no. 14, p. $365,2014$.

[2] G. C. Rakes, 'The effects of open book testing on student performance in online learning environments'. 2015.

[3] P. K. Agarwal and H. L. Roediger III, 'Expectancy of an open-book test decreases performance on a delayed closed-book test', Memory, vol. 19, no. 8, pp. 836-852, 2011.

[4] N. Mathew, 'Student Preferences and Performance: A Comparison of Open-Book, Closed Book, and Cheat Sheet Exam Types', 2012 NCUR, 2012.

[5] B. Sharma, 'A focus on reliability in developmental research through Cronbach's Alpha among medical, dental and paramedical professionals', Asian Pacific J. Heal. Sci., vol. 3, no. 4, pp. 271-278, 2016.

[6] R. M. Block, 'A discussion of the effect of open-book and closed-book exams on student achievement in an introductory statistics course', 
PRIMUS, vol. 22, no. 3, pp. 228-238, 2012.

[7] A. Gharib, W. Phillips, and N. Mathew, 'Cheat sheet or open-book? A comparison of the effects of exam types on performance, retention, and anxiety', Psychol. Res., vol. 2, no. 8, p. 469, 2012.

[8] S. G. Green, C. J. Ferrante, and K. A. Heppard, 'Using Open-Book Exams to Enhance Student Learning, Performance, and Motivation.', $J$. Eff. Teach., vol. 16, no. 1, pp. 19-35, 2016

[9] K. C. Williams and C. C. Williams, 'Five key ingredients for improving student motivation', Res. High. Educ. J., vol. 12, p. 1, 2011.
[10] H.-Y. Feng, J.-J. Fan, and H.-Z. Yang, 'The relationship of learning motivation and achievement in EFL: Gender as an intermediated variable', Educ. Res. Int., vol. 2, no. 2, pp. 50-58, 2013.

[11] O. A. Sogunro, 'Motivating factors for adult learners in higher education', Int. J. High. Educ., vol. 4, no. 1, p. p22, 2014.

[12] L. Myyry and T. Joutsenvirta, 'Open-book, open-web online examinations: Developing examination practices to support university students' learning and self-efficacy', Act. Learn. High. Educ., vol. 16, no. 2, pp. 119-132, 2015 . 